\title{
Erratum to: Nutritional and Structural Response of Potato Plants to Reduced Nitrogen Supply in Nutrient Solution
}

\author{
Dong Chil Chang ${ }^{1}$ - Yong Ik Jin ${ }^{1}$ - Su Jeong Kim ${ }^{1}$ - Sung Tae Park ${ }^{2}$. \\ Young Ryul Cho ${ }^{3}$. Yong Beom Lee ${ }^{4}$
}

Published online: 29 April 2016

(C) The Potato Association of America 2016

Erratum to: Am. J. Potato Res.

DOI 10.1007/s12230-016-9510-z

The second author's name has to be changed as follows:

Young Ik Jin $\rightarrow$ Yong Ik Jin.

In Fig. 2, the symbol of $\mathbf{N} 16$ days has to be changed from - $\mathbf{-}$ to - -. The correct Fig. 2 is printed here.

The online version of the original article can be found at http//dx.doi.org/ 10.1007/s12230-016-9510-z.

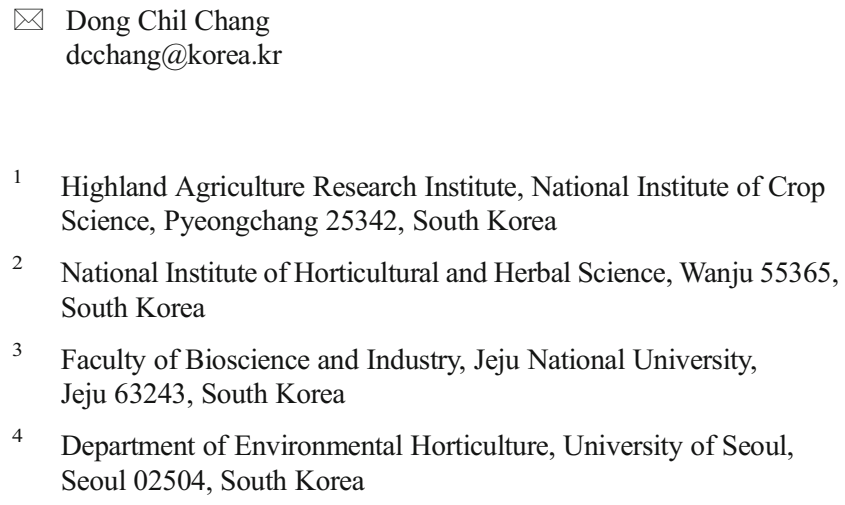

2 National Institute of Horticultural and Herbal Science, Wanju 55365, South Korea

3 Faculty of Bioscience and Industry, Jeju National University, Jeju 63243, South Korea

4 Department of Environmental Horticulture, University of Seoul, Seoul 02504, South Korea 


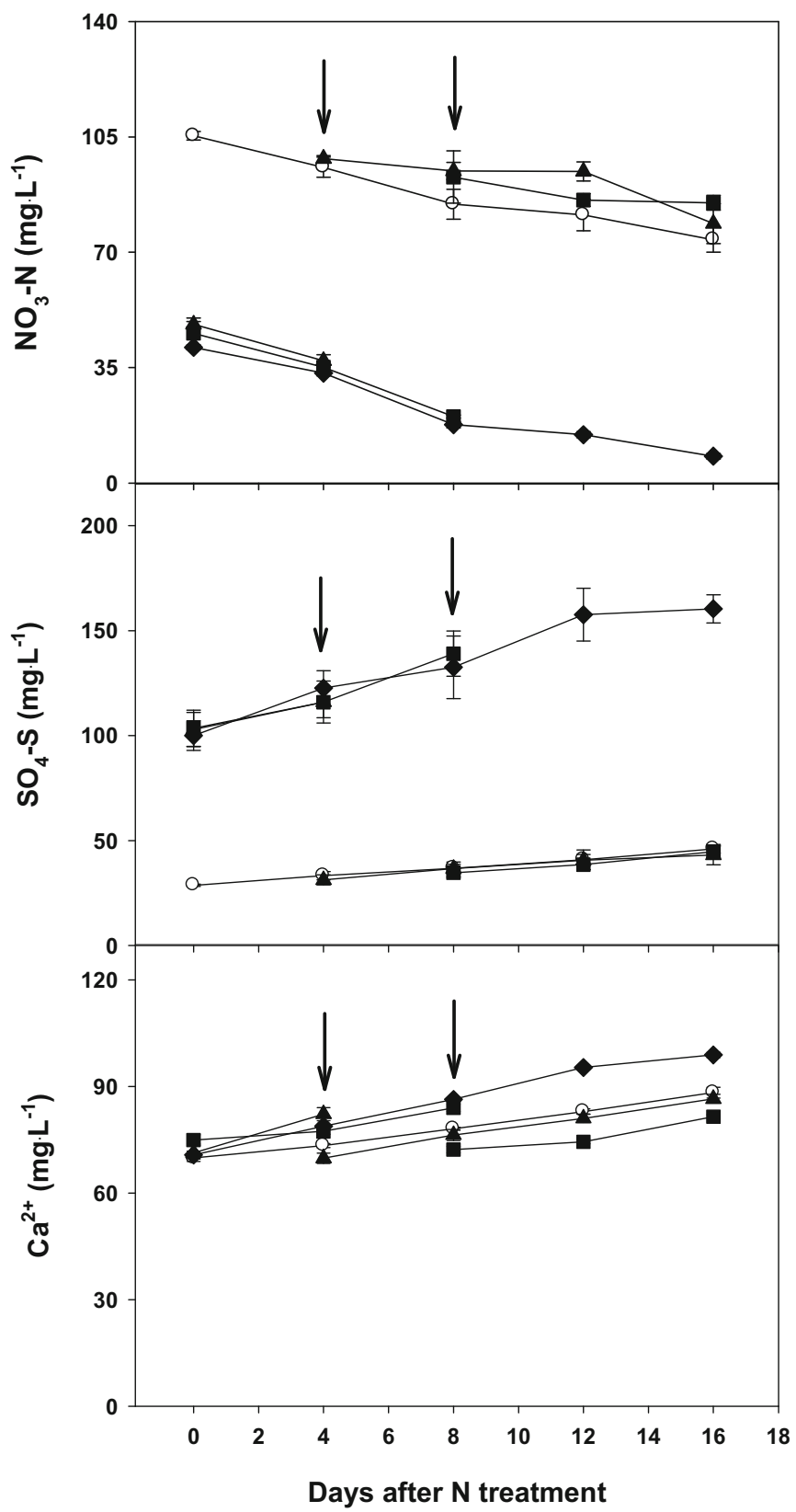

Fig. 2 Variations of each nutrient $\left(\mathrm{NO}_{3}{ }^{-}, \mathrm{PO}_{4}{ }^{3-}, \mathrm{SO}_{4}{ }^{2-}, \mathrm{K}^{+}, \mathrm{Ca}^{2+}\right.$, and $\mathrm{Mg}^{2+}$ ) with periods of reduced nitrogen supply. Plants were grown under reduced nitrogen supply for 4,8 , and 16 days and compared with

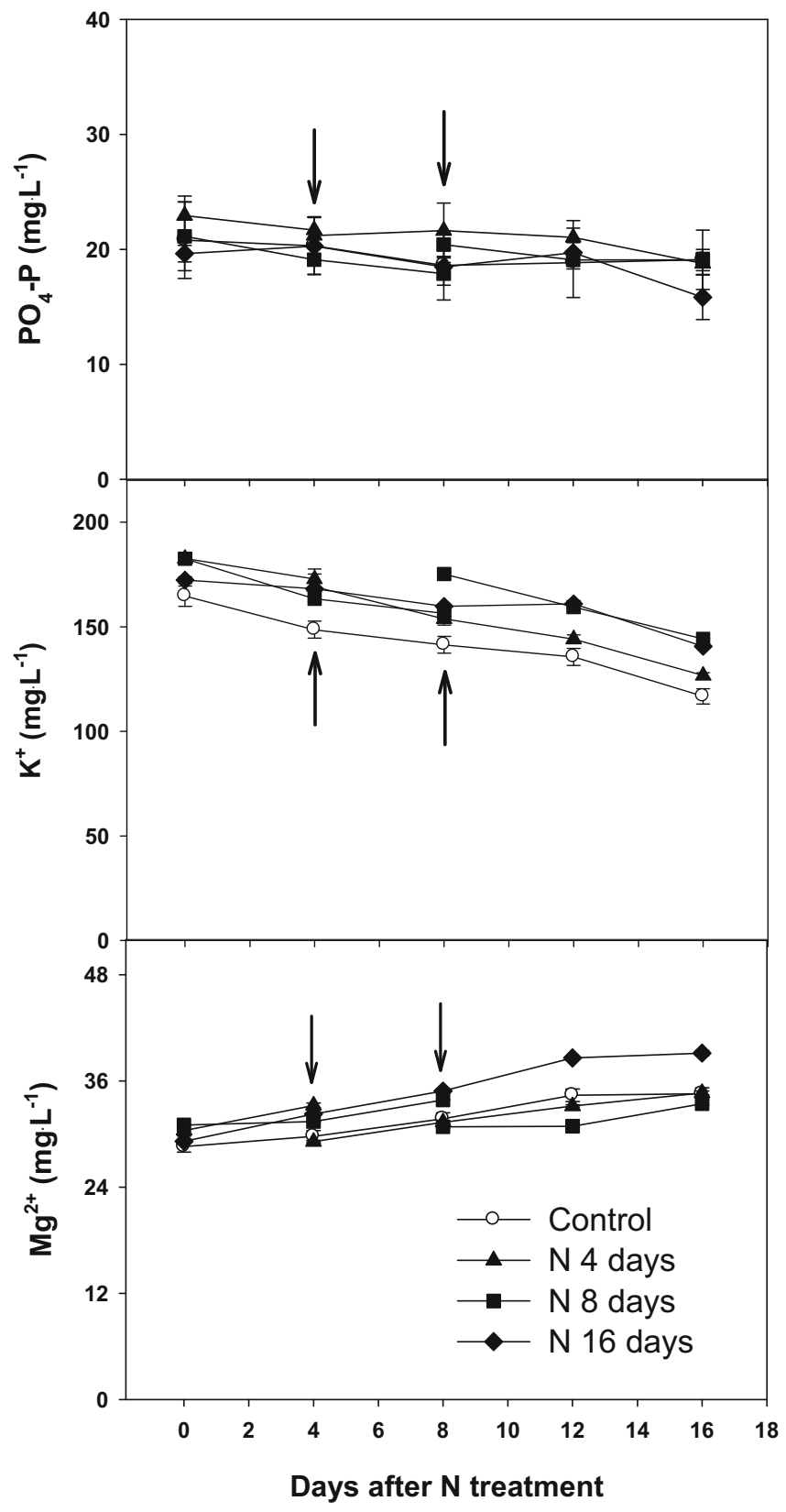

control plants which were grown under a constant supply of nitrogen. Arrows indicate the date when the reduced nitrogen solution is replaced with the control solution 